\title{
EXTERNALIDADES FISCALES INTERREGIONALES EN ARGENTINA: UN ANÁLISIS DE EQUILIBRIO GENERAL COMPUTADO ${ }^{1}$
}

\author{
Leonardo Javier Mastronardi ${ }^{*}$ \\ enviado: marzo 2013 - aceptado: mayo 2013
}

\begin{abstract}
Resumen
El objetivo del trabajo es analizar las externalidades fiscales pecuniarias provocadas al cambiar políticas fiscales a nivel regional o nacional en Argentina. Para el análisis se utiliza un modelo de equilibrio general estático bi-regional para la Ciudad de Buenos Aires y el resto de Argentina. Se analiza el impacto de políticas fiscales sobre el bienestar de los agentes privados y públicos y los efectos "derrame" asociados, mediante la utilización de simulaciones que consideran idéntico monto nominal de incremento en los impuestos. Los resultados del modelo muestran que las políticas fiscales tienen efectos negativos relevantes en los niveles de actividad y en el bienestar de los agentes. Además, se presenta un análisis de sensibilidad para la regla de ajuste de los salarios y para la movilidad del capital dado que son factores fundamentales en la determinación de los resultados cuantitativos.

Clasificación JEL: C68, D58, H77

Palabras clave: federalismo fiscal, equilibrio general computado, externalidades fiscales interregionales.
\end{abstract}

\begin{abstract}
The aim of this paper is to analyze the spillover effects of national and local tax policies in Argentina. For this objective, we consider a static bi-regional general equilibrium model for the Buenos Aires City and the rest of Argentina. We analyze the impact of fiscal policies on welfare of private agents and the spillover effects

\footnotetext{
*Universidad Argentina de la Empresa (UADE) - E-mail: 1mastronardi@uade.edu.ar - Tel (+54 11) 4010.7736

${ }^{1}$ El presente trabajo fue distinguido con el Premio Estudios Económicos 2013, correspondiente a la VI Edición del Congreso de Estudiantes de Posgrado en Economía, CNEPE, UNS.
} 
on the performance of the public sector of both regions using equal revenue tax increases simulations. As expected, the model shows that regional and national fiscal policies do have relevant effects on the activity level in the regions and on the welfare of their inhabitants. The paper presents a sensibility analysis, which considers changes in the rule of indexation of wages and in capital mobility. They are shown to be relevant for the quantitative results.

JEL Clasification: C68, D58, H77

Keywords: fiscal federalism, computable general equilibrium, fiscal interregional externalities.

\section{INTRODUCCION}

Los modelos de equilibrio general computado (CGE por sus siglas en inglés) han sido utilizados en las últimas décadas para analizar diferentes problemas entre regiones dentro de un país y dentro de bloques continentales. La mayoría de los trabajos analizan efectos de políticas de federalismo fiscal y tax competition. Cardenete (2009) analiza impactos de federalismo fiscal en Andalucía mediante un modelo bi-regional de equilibrio general estático para la región; también Cardenete y Sancho desarrollaron un CGE estático para analizar en la misma región una reforma fiscal en el impuesto al ingreso (2001) y cambios en impuestos nacionales (2002). Bhattarai (2007) estudia también el impacto sobre el bienestar de la economía de una reforma tributaria equivalente (por reemplazo de impuestos) en la economía del Reino Unido.

El presente trabajo muestra los resultados de un modelo CGE estático para Argentina preparado para simular políticas fiscales a nivel regional. En particular, se separa a la Argentina en dos regiones, la Ciudad Autónoma de Buenos Aires (CABA) y el resto del país (RP) como un agente consolidado. Se describe en el trabajo, tanto la construcción de la matriz de contabilidad social regional (RSAM) como la construcción y características principales del modelo de equilibrio general computado regional (CGE). El armado de la RSAM y del CGE regional se basan en el CGE de Argentina descripto por Chisari et. al. (2010). Se desarrolló una apertura regional de dicho modelo en las dos regiones descriptas con una minuciosa separación de agentes mediante la utilización de métodos de calibración. Por último, serán objeto de análisis del trabajo, la presentación de diferentes modificaciones impositivas equivalentes ex-ante en valor nominal mediante simulaciones estáticas. Dado que no existen a nivel regional ni un sistema de cuentas regionales 
ni matrices insumo producto interregionales, se debió realizar un trabajo exhaustivo para separar las cuentas nacionales entre las regiones para poder construir el modelo. El primer paso fue construir la matriz de insumo producto interregional sobre la base de métodos híbridos de calibración (métodos indirectos combinados con entropía cruzada para balancear la matriz) ${ }^{2}$.

La representación de la producción en cada región debe tener en cuenta tanto la localización de las actividades productivas, como la de los agentes (hogares) que perciben la remuneración de los factores productivos por parte de las empresas de modo de componer el gasto de las familias de ambas regiones. Esta cuestión es fundamental a la hora de analizar los efectos de equilibrio general de las políticas fiscales. Esto sucede porque el lugar donde se genera el ingreso puede diferir de la región donde se realiza el consumo (por ejemplo un individuo que compone un hogar del resto del país puede trabajar en CABA y consumir en el resto del país), dado que tanto el consumo como los ingresos son variables endógenas en el modelo de equilibrio general. Es por esto que se estimó con especial atención la matriz de generación del ingreso que describe la distribución de los ingresos factoriales para los hogares de CABA y del resto del país.

El modelo cuenta con diez sectores de actividad y dos tipos de hogares (rico y pobre) en cada región. Además incluye al sector externo y tres gobiernos, el nacional (que determina la política fiscal a nivel nacional), el gobierno de CABA (que determina la política fiscal local a nivel de CABA) y el gobierno de las provincias (que determina la política fiscal local en el resto del país).

El principal objeto de estudio del trabajo es el análisis en variaciones en el bienestar de los hogares, en el bienestar de los gobiernos y las tasas de ganancia de los sectores al modificarse las políticas fiscales nacionales y locales. La idea es poder identificar "ganadores" y "perdedores" en las modificaciones de política mediante la programación de simulaciones. En este trabajo, las simulaciones consideran cambios en las tasas efectivas de diferentes impuestos, con el objetivo de poder cuantificar los efectos directos e indirectos sobre los agentes de la región y las externalidades fiscales que se generan en los agentes de la otra región. El modelo muestra que existen externalidades fiscales relevantes al cambiar impuestos locales de una región sobre la otra región. Se analiza el impacto de variaciones en impuestos a la producción local en la región (específicamente a los usos de la producción donde el principal impuesto es "Ingresos Brutos") y en el valor agregado

\footnotetext{
${ }^{2}$ Véase Mastronardi, Romero y Chisari (2012) donde se detalla la metodología para la construcción de una matriz insumo producto bi-regional para la CABA.
} 
a nivel nacional. Para facilitar la comparación, la simulación supone un monto equivalente de aumento de la recaudación en cada caso.

El trabajo se divide en diferentes secciones y subsecciones. A continuación se presentan características de la Ciudad de Buenos Aires. Luego se plantea una sección con la metodología de construcción de la RSAM y luego otra con la construcción del modelo. Luego se presentan subsecciones que incluyen tres tipos de simulaciones de política fiscal en un escenario de salarios nominales constantes. Por último, se presentan subsecciones analizando la sensibilidad de los resultados a la regla de indexación salarial y a la movilidad del capital.

\section{I- INFORMACION Y BASE DE DATOS COMO INSUMO DEL CGE}

\section{I.1- Características socioeconómicas de la Ciudad de Buenos Aires}

La Ciudad de Buenos Aires fue convertida luego de la reforma constitucional del año 1994 en un distrito autónomo del gobierno nacional. Posee 202 kilómetros cuadrados y una población que ronda los tres millones de habitantes y compone el $7.2 \%$ de la población argentina. El PBI de la ciudad compone alrededor del $28 \%$ del PIB argentino a precios de mercado del año 2006 con el 34\% del consumo argentino y el 7\% de las exportaciones, siendo la región más rica del país con un PBI per cápita de U\$20.000 mientras que la media nacional era de U\$6.500 en 2006.

Dado que en el trabajo se examinarán variaciones en políticas fiscales y su impacto sobre el bienestar, la Tabla 2 desarrolla las fuentes de ingreso de los tres gobiernos (diferenciando impuestos nacionales -recaudados por el gobierno nacional- y locales -recaudados por el gobierno de CABA y el que representa la agregación de gobiernos provinciales como un consolidado-). Se observa que los impuestos a los usos de producción (ventas) conforman el 89\% de los recursos tributarios del gobierno de CABA (donde Ingresos Brutos compone el $72 \%$ del total), mientras que en el resto del país componen el $87 \%$ (Ingresos Brutos es el $71 \%$ del total). Como es de imaginar, las tasas impositivas efectivas en la CABA son superiores que en el resto del país, y esto se puede apreciar al observar que el $45 \%$ del Impuesto al Valor Agregado (IVA) se paga en la actividad de la CABA (que posee el $28 \%$ del PIB nacional como mencionamos). Conociendo los datos de PBI per cápita, es entendible que en la zona más rica del país bajo este indicador, el $7.2 \%$ de la población pague el $43 \%$ de los impuestos nacionales a los hogares. 
Tabla 1- Ponderaciones relativas en términos de los datos de Argentina (En millones de Pesos Argentinos)

\begin{tabular}{llll}
\hline Indicador & CABA & RP & Argentina \\
\hline Población & 0.07 & 0.93 & $40,117,096$ \\
PBI ${ }^{*}$ & 0.28 & 0.72 & 654,439 \\
Consumo & 0.34 & 0.66 & 465,429 \\
Inversión & 0.20 & 0.80 & 152,838 \\
Exportaciones & 0.07 & 0.93 & 162,035 \\
\hline
\end{tabular}

Fuente: Instituto Nacional de Estadísticas y Censos y Dirección General de Estadística y Censos (Ministerio de Hacienda GCBA). *A precios de mercado de 2006.

Tabla 2- Fuentes de financiamiento de los gobiernos. En porcentaje del total y en millones de pesos argentinos.

\begin{tabular}{lllll}
\hline Indicador & \multicolumn{2}{l}{ Porcentaje de la región } & \multicolumn{2}{l}{ Estructura } \\
\cline { 2 - 5 } & CABA & RP & CABA & RP \\
\hline $\begin{array}{l}\text { Recaudación de impuestos } \\
\text { nacionales (Millones de \$) }\end{array}$ & 53,271 & 104,404 & 1.00 & 1.00 \\
IVA & 0.452 & 0.548 & 0.33 & 0.20 \\
$\begin{array}{l}\text { Impuestos nacionales a los } \\
\text { usos de producción }\end{array}$ & 0.254 & 0.746 & 0.42 & 0.63 \\
$\begin{array}{l}\text { Impuestos a los hogares } \\
\begin{array}{l}\text { Recaudación de impuestos } \\
\text { locales (Millones de \$)** }\end{array}\end{array}$ & 0.434 & 0.566 & 0.26 & 0.17 \\
$\begin{array}{l}\text { Ingresos Brutos } \\
\begin{array}{l}\text { Otros impuestos a los usos } \\
\text { de producción }\end{array}\end{array}$ & 0.241 & 19,759 & 1.00 & 1.00 \\
$\begin{array}{l}\text { Impuesto a los hogares } \\
\text { Implo }\end{array}$ & 0.243 & 0.759 & 0.17 & 0.16 \\
\hline
\end{tabular}

Fuente: Instituto Nacional de Estadísticas y Censos (INDEC), Administración Federal de Ingresos Públicos (AFIP) y Dirección General de Estadística y Censos (Ministerio de Hacienda GCBA). * Recaudado por el gobierno nacional en ambas regiones. ${ }^{* *}$ Recaudado por los gobiernos provinciales y el gobierno de la CABA. 


\section{I.2 CONSTRUCCIÓN DE LA MATRIZ DE CONTABILIDAD SOCIAL REGIONAL (RSAM)}

La base de datos utilizada para la calibración del modelo de equilibrio general se obtuvo de una matriz de contabilidad social interregional especialmente construida que diferencia agentes económicos (sectores, hogares, gobiernos) según la residencia de los mismos.

A continuación se describen los aspectos fundamentales para el armado de la base. La matriz base de insumo producto utilizada está basada sobre la versión de 1997 publicada por el INDEC (2001), que fue reestimada luego para el año 2006 por Chisari et. al. (2010). Este trabajo fue utilizado también para el benchmark de la matriz de contabilidad social base a nivel nacional, sobre la cual luego se realiza la apertura regional de los agentes.

La matriz nacional de insumo producto fue separada en flujos intrarregionales e interregionales entre la Ciudad de Buenos Aires y el resto del país. La clave para su armado es la disponibilidad de información. Desafortunadamente, Argentina no posee un sistema de cuentas regionales (como poseen el Reino Unido y España, entre otros), por lo tanto la estimación de la matriz por métodos directos es compleja y costosa. Por este motivo, se han utilizado dos procedimientos adicionales de estimación indirecta para la construcción de la matriz insumo producto interregional y así obtener una separación en las compras intermedias de los sectores por región de residencia siguiendo las estimaciones del trabajo de Mastronardi, Romero y Chisari (2012) ${ }^{3}$.

La distribución de los ingresos factoriales se basa en la observada en 2006 en Argentina. Para la distribución en grupos y regiones de acuerdo a los microdatos se utilizó la Encuesta Permanente de Hogares (EPH) provista por el INDEC. Tanto en la RSAM como en el CGE, los hogares fueron modelados con dotaciones de trabajo que son ofrecidas en los mercados de factores de la CABA y del resto del país, es decir que el hogar del resto del país ofrece trabajo y capital a sectores localizados en la CABA y en el resto del país.

\footnotetext{
${ }^{3}$ La metodología de estimación indirecta para las estimaciones de las matrices intraregionales es la de coeficientes de localización (en particular el coeficiente aumentado de Flegg -AFLQ-) siguiendo a Jensen (1978) y Flegg y Webber (1997, 2000). Dado que la ciudad de Buenos Aires y el resto del país no poseen una estructura productiva idéntica, se utilizaron para la estimación agregada de la matriz regional métodos de entropía cruzada que es flexible para agregar restricciones tecnológicas siguiendo a Mastronardi, Romero y Chisari (2012) .
} 
La distribución de la canasta de consumo de bienes y servicios finales por parte de los hogares fue realizada en base a datos de la Encuesta Nacional de Gasto de los Hogares del 2005 (ENGHo 2005, INDEC) ( $^{4}$ La distribución del ingreso factorial y del consumo de los hogares a través de los sectores, se obtuvo aplicando el método de la entropía cruzada (Robinson, Cattaneo y El-Said, 2001). Para los gastos de los gobiernos (CABA, nacional y provinciales), se utilizaron datos de los gastos consolidados para el año 2006 obtenidos de la Dirección Nacional de Coordinación Fiscal con las Provincias del Ministerio de Economía de la Nación. Tanto la demanda como la oferta agregada computadas en la RSAM son consistentes con cuentas nacionales y regionales.

La información de la cuenta del gobierno fue obtenida de la Oficina Nacional de Presupuesto del Ministerio de Economía (ONPME). La RSAM distingue tres gobiernos: el nacional, el de la CABA y el del resto de provincias y municipios provenientes al resto del país. Para estimar el consumo público, se tomó la dimensión de los gobiernos sobre la base de los gastos ejecutados por la nación, las provincias y la CABA según la ONPME. La información sobre impuestos nacionales (coparticipables y no coparticipables) e impuestos locales fue obtenida de la AFIP, la Dirección General de Estadísticas y Censos (DGEyC) del gobierno de la CABA $\mathrm{y}$ de los ministerios provinciales.

El modelo incluye 10 sectores productivos, uno para actividades primarias, otro de industria manufacturera y ocho de servicios. Tres factores productivos son utilizados para la producción: trabajo, capital específico y capital móvil. El trabajo se supone móvil a lo largo de los sectores dentro de la región. El capital específico se supone fijo en los sectores regionales y el capital móvil puede trasladarse entre sectores y regiones de acuerdo a las tasas de ganancia.

La Tabla 3 presenta la participación de cada sector en términos de valor agregado nacional y en la estructura de la región. Estos sectores son los desagregados en la RSAM.

\footnotetext{
${ }^{4}$ Para la distribución regional del consumo entre hogares y sectores de las diferentes regiones (por ejemplo la cantidad de alimentos en el resto del país que consume el hogar pobre de CABA) se utilizó entropía cruzada sobre la base de datos sobre el consumo agregado de los hogares de CABA en la ENGHo para la orla fila y los totales sectoriales para la orla columna.
} 
Tabla 3- Valor agregado en Argentina (2006) Distribución y estructura entre regiones.

\begin{tabular}{lllll}
\hline Sectores & \multicolumn{3}{l}{ Distribución Regional } & \multicolumn{2}{l}{$\begin{array}{l}\text { Estructura de la } \\
\text { Región }\end{array}$} \\
\cline { 2 - 5 } & CABA & RP & CABA & RP \\
\hline Primario & 0.06 & 0.94 & 0.03 & 0.19 \\
Industria Manufacturera & 0.24 & 0.76 & 0.17 & 0.21 \\
Electricidad, Gas y Agua & 0.22 & 0.78 & 0.01 & 0.02 \\
Construcción & 0.24 & 0.76 & 0.05 & 0.06 \\
Comercio & 0.24 & 0.76 & 0.10 & 0.13 \\
Restaurantes y Hoteles & 0.47 & 0.53 & 0.05 & 0.02 \\
Transporte y comunicaciones & 0.39 & 0.61 & 0.12 & 0.07 \\
Intermediación Financiera & 0.56 & 0.44 & 0.10 & 0.03 \\
Actividades inmobiliarias y & 0.51 & 0.49 & 0.21 & 0.08 \\
empresariales & & & & \\
Sector público y otros secto- & 0.25 & 0.75 & 0.17 & 0.19 \\
res privados & & & & \\
Total & 0.28 & 0.72 & 1.00 & 1.00 \\
\hline
\end{tabular}

Fuente: Instituto Nacional de Estadísticas y Censos y Dirección General de Estadística y Censos (Ministerio de Hacienda GCBA).

La Tabla 3 muestra que la CABA se especializa en sectores oferentes de servicios, especialmente en Intermediación Financiera y Actividades inmobiliarias y empresariales. Por otro lado, los sectores del resto del país se especializan principalmente en actividades Primarias, Industria y Construcción.

La RSAM posee un agente representativo del resto del mundo. Éste provee y contrata bienes y servicios por medio de exportaciones e importaciones a ambas regiones por separado. En el 2006, según los datos provenientes de la Balanza de Pagos del Banco Central de la República Argentina, la cuenta corriente y la balanza de pagos tenían un resultado positivo.

Un resumen simplificado de la RSAM se presenta a continuación en la Tabla 4. La misma posee un sector productivo, dos factores (trabajo y capital), impuestos nacionales, impuestos provinciales e inversión pública y privada para 
cada región, además del sector productivo del resto del mundo (ROW). Las columnas muestran la composición de los gastos de cada agente mientras que las filas representan los mercados.

La matriz insumo producto regional, es una submatriz de la RSAM que representa transacciones entre los sectores productivos (sectores, sectores). Debajo se encuentra la matriz de demanda factorial (factores, sectores) seguida por la matriz de impuestos locales y nacionales pagados por cada actividad (impuestos, sectores). En la matriz extendida utilizada en el modelo, se separan los impuestos pagados por uso de producción (exportaciones, ventas intermedias, consumo final e inversión). Finalmente, se incluye un vector de insumos importados (ROW, sectores) $)^{\mathbf{5}}$. El total de las filas y columnas de cada sector representa el respectivo valor bruto de producción regional.

La cuenta de factores muestra la matriz distribución del ingreso en términos de la remuneración recibida por los hogares como contraparte de los factores ofrecidos (Hogares, Factores). Parte del capital es contratado por el resto del mundo (ROW, Factores) en concepto de ganancias y dividendos girados al exterior y afines.

Por el lado de la demanda, observamos una resumida matriz de gasto de los hogares (Sectores, Hogares), así como también consumo de los gobiernos (Sectores, Gobiernos) e inversión privada (Sectores, Inversión Privada) y pública (Sectores, Inversión Pública). Las transferencias entre agentes vienen dadas por las matrices (Hogares, Hogares) y (Hogares, Gobierno).

Tanto el ahorro privado y el público como el del resto del mundo se suman al modelo para financiar la inversión. La fila superávit (o déficit) indica el sobrante (faltante) de dinero de los agentes que corresponde al año 2006 y permite cumplir la ley de Walras en el modelo. Para los hogares, dicho superávit o déficit funciona como un "bono" que cierra la restricción presupuestaria. El gobierno de la CABA posee un superávit (luego de recibir la coparticipación por parte del gobierno nacional de 803 millones de pesos) de 144 millones de pesos. El gobierno del resto del país en términos consolidados (provincias y nación) posee un superávit $25.547 \mathrm{mi}-$ llones de pesos. Este superávit se financia en el modelo con el superávit de la balanza comercial respecto al resto del mundo, que ascendió a 29.511 millones de pesos.

\footnotetext{
${ }^{5}$ En el modelo, un importante supuesto es que las importaciones son consideradas como un bien compuesto. Esto implica que las mismas conforman una canasta de bienes transables que cada agente (ya sea consumidor o productor) compra en la misma proporción los bienes tomando la hipótesis de bienes de tipo Leontief.
} 


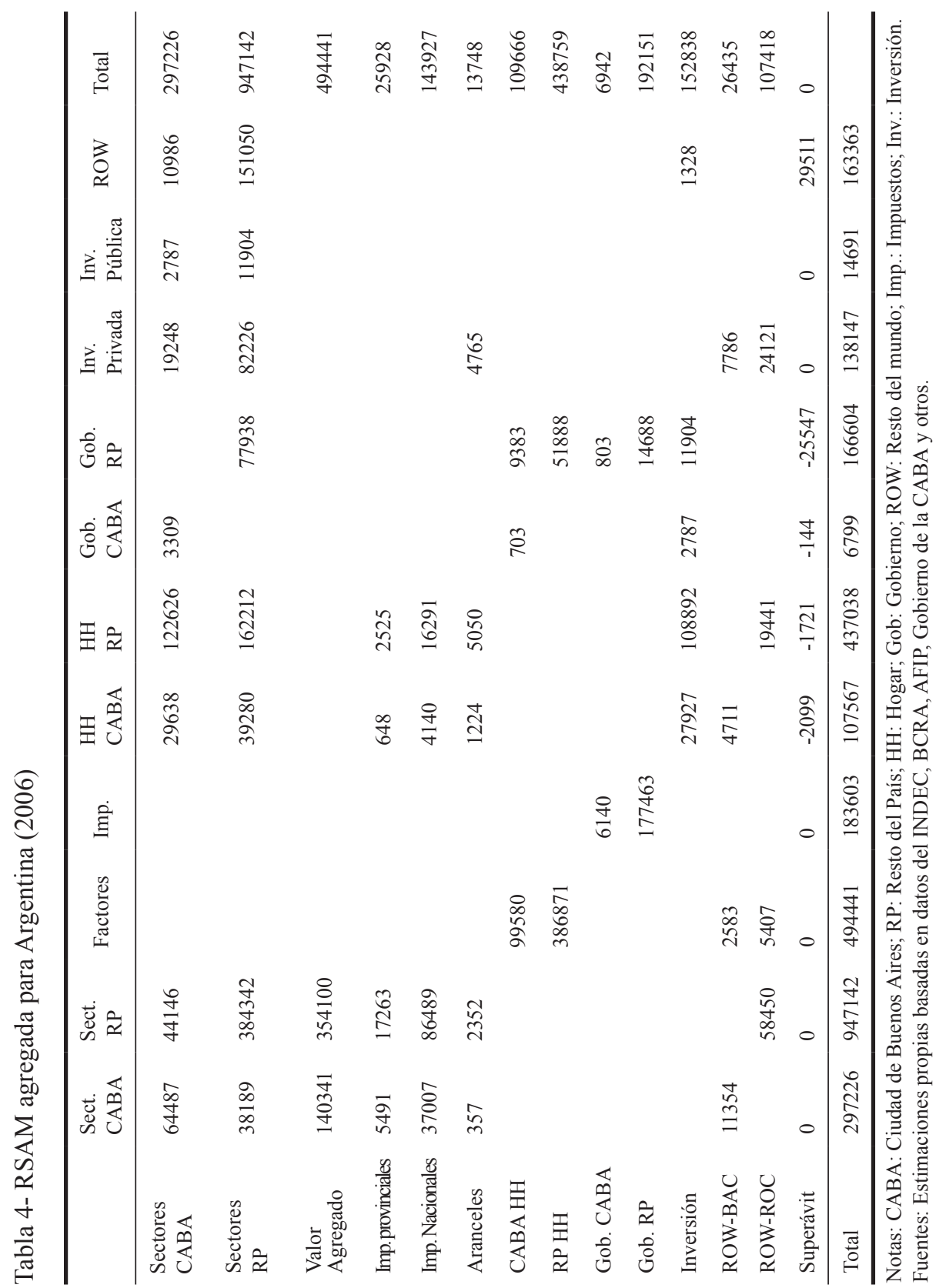


La RSAM extendida (y utilizada en el CGE) divide al gobierno del resto del país en gobierno nacional y gobiernos provinciales y municipales. Esto es importante dado que se modela especialmente la coparticipación mediante el cómputo de una transferencia por parte del gobierno nacional a las provincias y a la CABA. Dado esto, se incluye en la RSAM una división de los impuestos nacionales en su carácter de coparticipables o no según lo indica la Ley Nacional de Coparticipación Federal de Impuestos (LN N ${ }^{\circ}$ 23.548). En el 2006, según los datos del Ministerio de Economía (gastos de los gobiernos) cruzados con datos del INDEC y AFIP (recursos tributarios), el gobierno nacional tuvo un superávit de 23738 millones de pesos y el conjunto de gobiernos provinciales tuvieron también un superávit de 1809 millones de pesos (luego de recibir coparticipación por parte del gobierno nacional de 44237 millones de pesos).

\section{II- CARACTERISTICAS DEL MODELO DE EQUILIBRIO GENERAL COMPUTADO REGIONAL}

El modelo de equilibrio general computado regional posee agentes maximizadores de funciones de utilidad o beneficio que se restringen a los respectivos conjuntos presupuestarios. El modelo cuenta con dos hogares representativos (rico y pobre) por región, tres gobiernos (CABA, provincias y nacional) y el resto del mundo. Existen 10 sectores productivos en cada región que producen un bien homogéneo. El mismo se produce con insumos intermedios (adquiridos tanto en la región de residencia como en la otra región), con factores provenientes de la región (suponemos que el trabajo y el capital físico no son móviles entre regiones) y con capital móvil. El capital móvil está modelado como una proporción $(\theta)$ del capital que se reasigna en los sectores de ambas regiones de acuerdo a las variaciones en las tasas de ganancias. Diferentes elasticidades de sustitución fueron utilizadas para los bienes tanto para usos finales como intermedios en las funciones de producción y utilidad. El modelo es flexible para imputar diferentes tipos de funciones de utilidad y producción sobre la base de cambios en parámetros y elasticidades, así como también es flexible en términos de la movilidad factorial. Una descripción simplificada del modelo se presenta en el apéndice al final del trabajo.

Como punto importante, el modelo posee una importante descomposición de los recursos fiscales en la RSAM por tipo de gobierno, dado que este punto es central en el análisis de federalismo fiscal. Así pueden distinguirse impuestos nacionales recaudados por el gobierno nacional e impuestos provinciales donde el agente recaudador son las provincias y el gobierno de la CABA. Entre los nacio- 
nales, el modelo a su vez distingue entre impuestos coparticipables (como el IVA o ganancias) y los no coparticipables (como al comercio exterior). Esto es fundamental al realizar las simulaciones, ya que la coparticipación funciona como una transferencia del gobierno nacional a las provincias. Por lo tanto, si la simulación aumenta el IVA, hay un efecto indirecto sobre los gobiernos provinciales que se benefician por el aumento de la coparticipación. Esto no ocurre si por ejemplo se aumentan los impuestos al comercio exterior.

El CGE posee todas las propiedades del enfoque walrasiano de equilibrio general y se resuelve numéricamente gracias a la interface MPSGE del programa GAMS $^{6}$ siguiendo a Brooke et al. (1992) y a Rutherford (1999). Esto permite simular computacionalmente los impactos de las políticas fiscales en ambas regiones.

El modelo permite estimar para cada región el bienestar de cada agente y las tasas de ganancia de los sectores ante cambios en la política fiscal que conforman el objetivo del trabajo. La idea es poder identificar "ganadores" y "perdedores" ante cambios en la política impositiva y ver qué externalidades fiscales genera sobre las regiones por separado. Así se podrán cuantificar las variaciones de bienestar de agentes del resto del país cuando la CABA cambia la política impositiva. El modelo también admite modificaciones en los precios relativos y en los niveles de actividad mediante cambios en elasticidades de sustitución y movilidad de factores. Estos pueden ser la fuente para la explicación de los efectos positivos y negativos sobre las industrias y los hogares de las simulaciones.

Como es usual en los modelos de equilibrio general, los precios en simultáneo son los que vacían los mercados y este es el método de cierre del modelo. Cabe destacar la excepción presente en el mercado de trabajo, dado que en el año 2006 el mercado no se hallaba en equilibrio (la tasa de desempleo de la Argentina era $11.4 \%$ y la de la CABA era $9.1 \%$ ), por lo tanto los salarios admiten desempleo. Para esta versión fue adaptado el CGE para Argentina presentado por Chisari et. al (2010).

\footnotetext{
${ }^{6}$ El GAMS es un programa de optimización, que se puede adaptar para maximizar una función objetivo neutral sujeta a las ecuaciones constitutivas del modelo de equilibrio general; sin embargo, no todas las estructuras walrasianas o de equilibrio general pueden ser reducidas a modelos de optimización. El enfoque de complementariedad permite abordar estos casos (por ejemplo, los salarios mínimos). El MPSGE es un programa que posee la estructura Walrasiana y disminuye los costos de programación del modelo dado que al cargarle la matriz de contabilidad social el mismo esta autocalibrado. Se puede trabajar simultáneamente con ambos, aprovechando entonces las ventajas de uno y otro; tal es la estrategia seguida en el modelo que aquí presentamos.
} 
Por el lado de la oferta, la función de producción anidada de cada sector fue modelada como de tipo Leontief entre el valor agregado y los insumos intermedios. Asimismo, la función de producción de los insumos intermedios es una función de tipo Leontief entre todos los bienes, que son complementarios perfectos en la producción. Por otro lado, la función de valor agregado se modeló con una función tipo Cobb-Douglas de los factores de producción (trabajo, capital específico y capital móvil).

De esta manera, el producto $x$ proveniente de la región $i$ se produce mediante valor agregado y consumo intermedio. El consumo intermedio es otra función anidada en la cual la elasticidad de sustitución entre los bienes y servicios es 0 por la hipótesis de Leontief. En cambio, el valor agregado utiliza elasticidad de sustitución unitaria entre los factores y los coeficientes de la función Cobb-Douglas vienen dados por el porcentaje de participación en el output. Dicha estructura de producción se puede observar en la Figura 1.

Figura 1- Estructura de producción

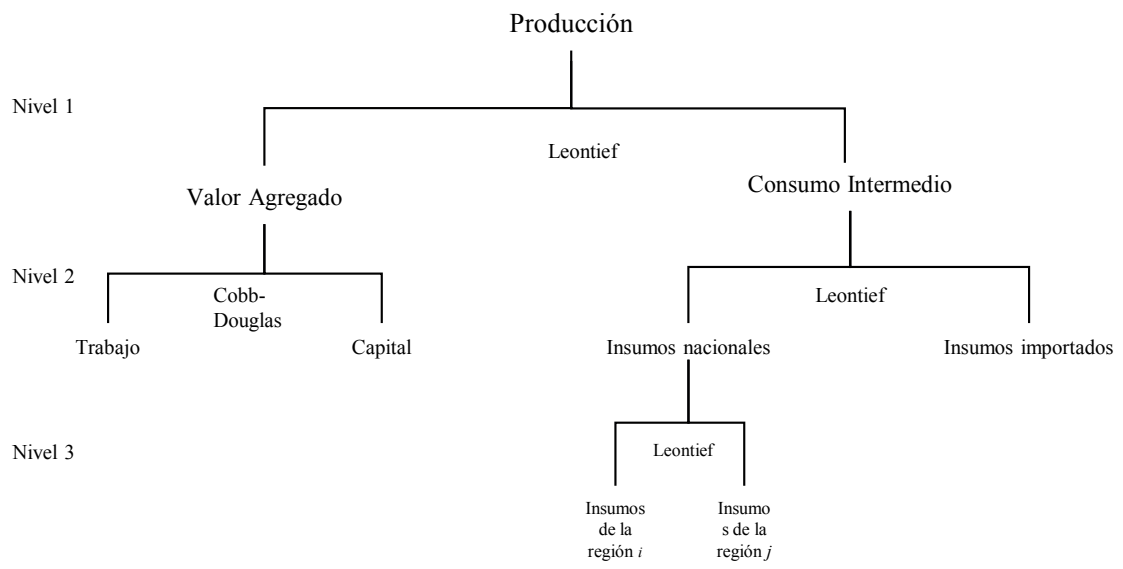

Por el lado de la demanda se modelaron cuatro hogares representativos (dos en cada región divididos por niveles de ingreso), un gobierno nacional, un gobierno de la CABA, otro gobierno que representa el consolidado de gobiernos provinciales y municipales del resto del país y el sector externo.

Los hogares poseen funciones de utilidad anidada de tipo Cobb-Douglas y compran y venden bienes de consumo final de ambas regiones e importados 
generando el bien consumo y de inversión de la región de residencia e importados mediante una función de inversión. Los individuos terminan minimizando el costo de la canasta óptima de acuerdo a los ingresos laborales y a las transferencias que reciben de los diferentes gobiernos. La estructura del consumo final puede observarse en la Figura 2. La misma muestra la decisión de los hogares respecto a la canasta de bienes que maximiza la función de utilidad. Como se mencionó anteriormente la elasticidad de sustitución entre los bienes de diferentes procedencias es unitaria con la función Cobb-Douglas.

Figura 2- Estructura de consumo final

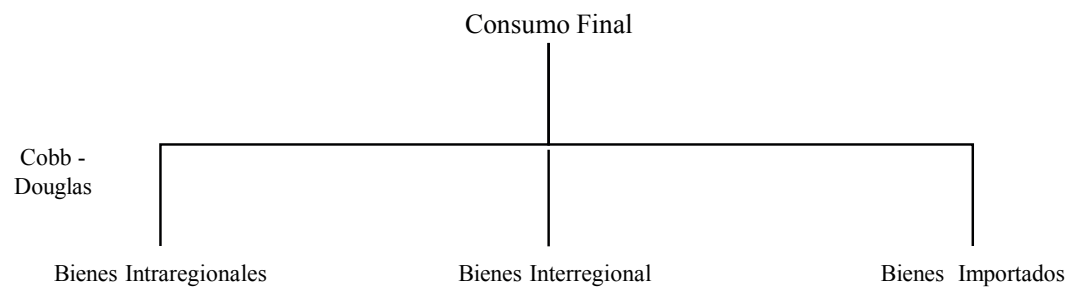

Cada gobierno es un agente que participa en los mercados para invertir, consumir, recibir y ofrecer transferencias a los hogares y entre los gobiernos mediante una función de utilidad Cobb-Douglas; y están restringidos en términos presupuestarios a la recaudación percibida y a los fondos coparticipables que correspondan, así como también realiza transacciones financieras en el mercado de bonos.

El sector externo compra las exportaciones al resto del mundo de ambas regiones y les vende importaciones, tomando dividendos de las inversiones y realizando transacciones en el mercado de bonos. Esto implica como regla de cierre que no existe balanza comercial sino que la misma se compensa con movimientos financieros compensatorios en el mercado de bonos. Como mostramos en la RSAM, las cuentas nacionales de Argentina muestran que en el 2006 se pagó deuda, por lo tanto el modelo implícitamente no permite que los gobiernos emitan nueva deuda y la balanza de pagos será variable pero positiva.

Respecto a las dotaciones factoriales, el capital se utiliza en plena capacidad (ausencia de capacidad ociosa). Existen nueve tipos de dotaciones factoriales (dotación de trabajo y capital de la región $j$ proveniente del hogar $h$ y el capital móvil). El modelo tiene en cuenta que los hogares de CABA y del resto del país 
ofrecen en ambos mercados de trabajo sus servicios, por lo tanto el trabajo y el capital empleado por las industrias de CABA en realidad es un compuesto de factores ofrecidos por habitantes de CABA y habitantes del resto del país y viceversa. Para esta versión del modelo, se toma el supuesto que los hogares no pueden transformar las dotaciones de trabajo de una región en dotaciones de trabajo para ofrecer en la otra región (esto puede suplirse mediante funciones de producción de trabajo que utilicen las familias con ciertas elasticidades de transformación con un agregado de trabajo como dotación).

La modelización del desempleo es un factor interesante para el caso argentino. El supuesto de pleno empleo puede modificar los beneficios de la liberalización del comercio como sugieren modelos con pleno empleo (Diao et. al., 2005), incrementando la demanda de trabajo (vía aumento en las exportaciones y en los niveles de actividad) lo que conlleva a salarios reales más altos, de manera que se erosiona el origen de la ventaja comparativa. En cambio, en los modelos con desempleo los salarios reales se mantienen constantes y las exportaciones crecen en mayor medida. Diferentes tasas de desempleo son aplicadas en las regiones de acuerdo a los datos relevados en el INDEC y expuestas en la sección anterior.

Al utilizar modelos walrasianos de equilibrio general que poseen desequilibrio en el mercado de trabajo por la presencia del desempleo, es esencial incluir una regla de ajuste de los salarios que conforme una ecuación aparte para considerar el desequilibrio. En el trabajo se consideran dos tipos de reglas de ajuste salarial: salarios nominales constantes (no indexados) y salarios indexados en términos reales por un índice de precios específico. El primero representa la restricción de un nivel salarial mínimo y el resultado se desarrollará en la presente subsección. El segundo es un poco más profundo, porque al fijar un salario real en una economía regional se debe prestar atención al nivel de precios (nacional o local) a utilizar. Dadas estas cuestiones, se presenta en la sección de resultados un análisis de sensibilidad a la regla de ajuste de los salarios.

\section{III- ANÁLISIS DE RESULTADOS DEL MODELO DE EQUILIBRIO GENERAL}

En esta sección se presentan los resultados de tres políticas fiscales, equivalentes en términos de monto de recaudación (equal revenue tax increase). Así, las simulaciones analizan un aumento de $\$ 1.000$ millones de pesos en tres conjuntos de impuestos: 
1- TUSOC: Incremento en los impuestos a los usos de la CABA (18.2\%) recaudados por el Gobierno de la CABA.

2- TUSOP: Incremento en los impuestos a los usos en el resto del país (5.8\%) recaudados por las provincias del resto del país.

3- IVA: Incremento en el impuesto al Valor Agregado en todo el país (2.1\%) recaudado por el gobierno nacional.

Las simulaciones permiten observar los impactos sobre el PIB, la inversión, el consumo público y privado en términos reales en ambas regiones, además de efectos sobre el empleo, los niveles de actividad y el bienestar de los gobiernos y hogares. Los resultados de las mismas se miden como desviaciones respecto a la base de calibración contenida en la RSAM.

La idea central del trabajo es analizar los efectos de las políticas sobre los agentes de la región en cuestión, y los efectos spillover generados a los agentes de la otra región. Como los resultados son sensibles a la regla de indexación del salario bajo desempleo y a la movilidad del capital, la subsección IV.4 analiza el caso de salarios reales constantes, y la subsección IV.5 presenta un análisis de sensibilidad a la movilidad del capital.

La Tabla 5 muestra los resultados de las simulaciones suponiendo que la regla de ajuste de los salarios es el mantenimiento de salarios nominales constantes y con una proporción de capital móvil entre regiones y sectores del 12\% (variable $\theta$ ) que es la utilizada por Chisari et al. (2010) para modelos dinámicos de equilibrio general para la Argentina.

El primer bloque de indicadores es macroeconómico. Se muestran variaciones porcentuales para cada región y el efecto correspondiente a nivel nacional en indicadores de la oferta global (PBI a costo de factores -PBI pb-, PBI a precios de mercado (PBI pm) que incluye los impuestos nacionales y provinciales e importaciones) y de demanda global (Consumo público y privado, inversión y exportaciones) así como un indicador del índice de precios al consumidor en cada región.

El segundo bloque tiene relación directa con el bienestar de los agentes privados. Así a nivel de las empresas se observan las variaciones en los sectores primario (SP), industrial (SS) y terciario o de servicios (ST). Luego se muestra en ambas regiones las tasas de desempleo simuladas, donde el benchmark de CABA era $9.1 \%$ y del resto de Argentina $11.4 \%$. Por último, se agrega la variación equivalente en el bienestar de los hogares rico y pobre en cada región. 


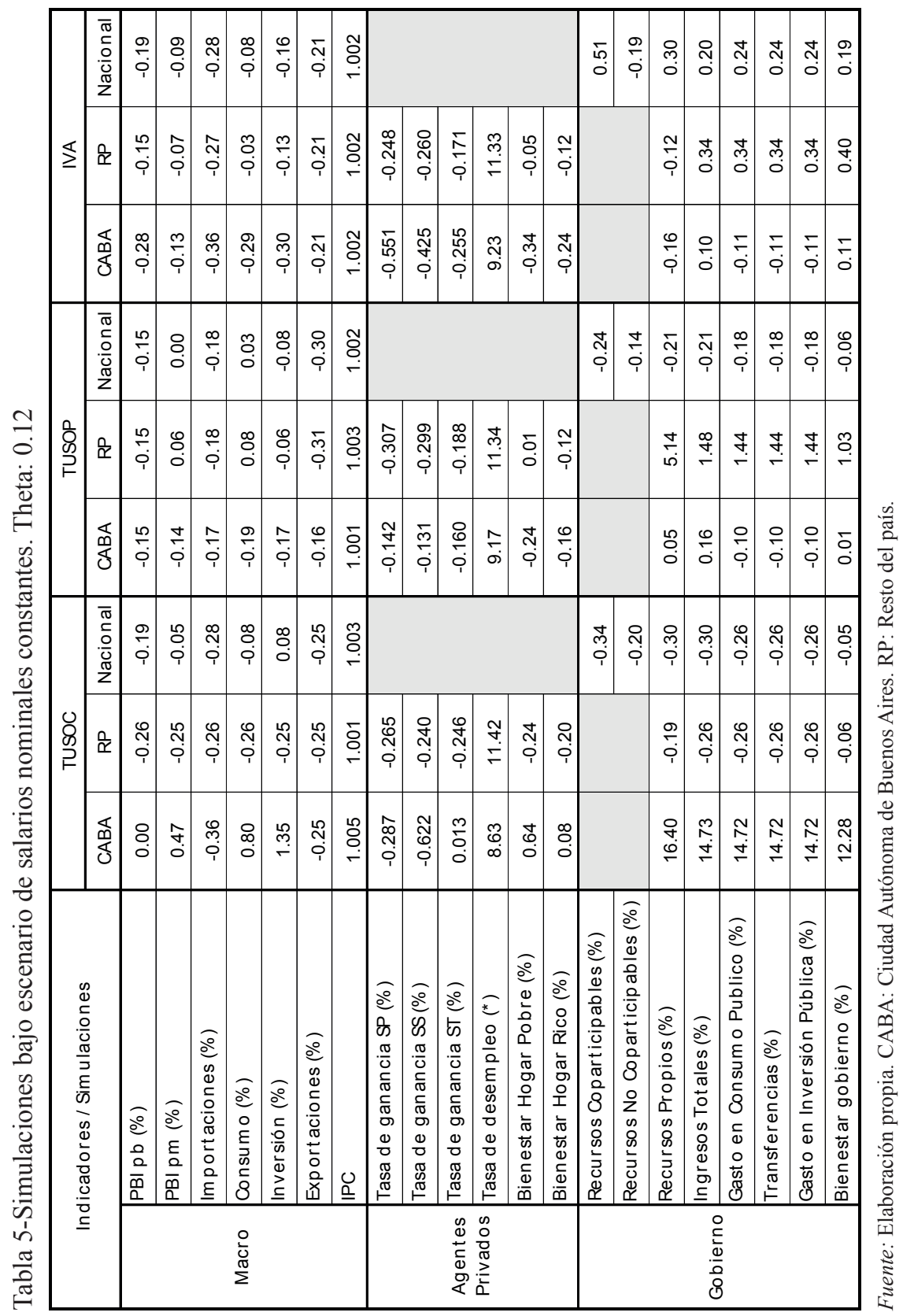


El último bloque presenta estadísticas fiscales del gobierno nacional federal y de los gobiernos provinciales y de la CABA. Las primeras dos filas muestran la variación en la composición de los recursos tributarios nacionales (de acuerdo a la variación de impuestos coparticipables o no). La tercera fila muestra la recaudación propia de cada gobierno y la cuarta los ingresos totales después de coparticipación. Por último, se muestra la variación en el consumo y la inversión pública y las transferencias y la variación equivalente de bienestar para los tres tipos de gobierno.

\section{III.1 - Análisis de la primera simulación}

De la primera simulación (TUSOC), se aprecia que en la CABA se produce aumento del PBI a precios de mercado (contiene la suba de impuestos) en contraposición a la caída de las importaciones. Esto se refleja por el lado de la demanda, mediante un incremento del consumo y la inversión (canalizado por el incremento del sector construcción que paga bajas tasas efectivas de los impuestos modificados) aunque disminuyen las exportaciones (menos que proporcionalmente con lo cual se refuerza el superávit de balanza comercial). La suba de impuestos produce una suba en los precios de los bienes de consumo de CABA. Dado que los salarios son constantes en términos nominales (no fueron indexados por el IPC), el aumento de precios provoca una caída del salario real que incrementa la demanda laboral (por la caída de los costos de contratación en términos reales) y que causa la caída de la tasa de desempleo.

Respecto a los indicadores del resto del país, se observa la presencia de efectos spillover fiscales negativos sobre la región, dado que todas las variables de oferta y demanda global disminuyen de manera similar. Como el efecto derrame no tiene tanto impacto en el nivel de precios, la tasa de desempleo aumenta, producto de la caída en la tasa de ganancia del capital (que genera una caída de la productividad marginal del trabajo por complementariedad en la función de producción), provocando una baja en los niveles de actividad de los sectores.

En términos de bienestar de las empresas, las tasas de ganancia de los sectores del resto del país disminuyen así como también en los sectores primario e industrial de la CABA. Por el contrario, los aumentos en los niveles de actividad de los sectores de servicios del gobierno, intermediación financiera y construcción apenas hacen positiva la tasa de ganancia promedio del sector de servicios. Si observamos los hogares de CABA, ambos incrementan su bienestar, siendo notorio el caso del hogar pobre que es el principal receptor del aumento de las transferencias del gobierno local y reforzando la mejora de bienestar con la baja en la tasa de 
desempleo. En cambio, los hogares del resto del país ven caer su bienestar como consecuencia de la caída en las transferencias por parte de los gobiernos regional y nacional y el aumento en la tasa de desempleo del resto del país.

Mirando el bienestar de los gobiernos, el gobierno de CABA aumenta su bienestar mientras que el gobierno nacional y el de las provincias ven un pequeño detrimento en el mismo.

\section{III.2 - Análisis de la segunda simulación}

De la segunda simulación (TUSOP), se observan también externalidades fiscales dado que en la CABA se produce una disminución del PBI a precios de mercado (y a costo de factores) reforzado a la caída de las importaciones. Esto se refleja por el lado de la demanda con la caída de todos los componentes de la demanda agregada.

Respecto a los indicadores del resto del país, se observa una disminución en el PBI a costo de factores (aumenta contemplando los impuestos en el PBI pm) y de las importaciones. Por el lado de la demanda se observa que caen la inversión y las exportaciones (en mayor proporción que las importaciones) pero aumenta el consumo. La política impositiva lleva a un aumento en el nivel general de precios que hace disminuir la tasa de desempleo en el escenario de salarios reales fijos.

En términos de bienestar de las empresas, las tasas de ganancia caen tanto en la CABA (de manera más o menos homogénea) como en los sectores del resto del país (siendo los sectores primario y secundario los más perjudicados).

Si observamos los hogares de CABA, ambos perciben una disminución de bienestar como consecuencia del aumento en la tasa de desempleo y la disminución de las transferencias nacionales y locales. En cambio, los hogares del resto del país tienen resultados contrapuestos dado que el hogar rico percibe una caída de bienestar (producto de la caída en la tasa de ganancia de los sectores y la disminución de transferencias nacionales) mientras que el pobre percibe un pequeño incremento en el bienestar (beneficiado por la disminución en la tasa de desempleo y el aumento de transferencias provinciales). Mirando el bienestar de los gobiernos, el gobierno de CABA aumenta su bienestar de manera poco significativa, ${ }^{7}$ mientras que el nacional disminuye su bienestar y el de las provincias se incrementa.

\footnotetext{
${ }^{7}$ Es un resultado que puede ser poco intuitivo pero se desprende de observar la variación en la recaudación provincial que aumenta un $0.05 \%$. Se observa una pequeña variación negativa en la recaudación de impuestos provinciales al consumo intermedio y a las inversiones pero un aumento significativo en la recaudación de impuestos al consumo (provocados por el aumento del consumo interregional).
} 
Comparando respecto al efecto de la primera simulación, las externalidades fiscales sobre la CABA son menos importantes dado que un aumento equivalente de impuestos provinciales ( $\$ 1.000$ millones de pesos) genera una menor caída en el PBI de la otra región, así como también de las tasas de ganancia de los sectores fuera de la región y el bienestar de los hogares. Este efecto se produce principalmente por la imposibilidad de sustitución a nivel de producción de insumos interregionales dado que fueron modelados como bienes Leontief como se mostró en secciones anteriores.

\section{III.3 - Análisis de la tercera simulación}

De la tercera simulación (IVA), se observan externalidades fiscales en ambas regiones pero con efectos disímiles entre las regiones. Tanto en la CABA como en el resto del país caen todos los componentes de la oferta y demanda agregada pero en la CABA se ven reforzados los efectos. Esto se debe a la composición sectorial del PIB y a que la tasa de evasión del impuesto legal es menor en el resto del país. Por lo tanto, la tasa efectiva del impuesto es mayor en la CABA y los sectores están más perjudicados.

La política impositiva lleva a un aumento en el nivel general de precios que hace disminuir la tasa de desempleo en el resto del país producto del escenario de salarios reales cayendo pero los mismos no llegan a compensar el efecto negativo en la CABA (donde aumenta la tasa de desempleo).

En términos de bienestar de las empresas, las tasas de ganancia caen tanto en la CABA (de manera más acentuada) como en el resto del país (siendo los sectores primario y secundario los más perjudicados en ambas regiones).

Si observamos los hogares todos disminuyen su bienestar, siendo los de CABA los más perjudicados. Se observa una asimetría en los efectos regionales ya que en CABA los más perjudicados son los pobres pero en el resto los ricos. Esto se debe a que el incremento de transferencias nacionales es recibido en mayor proporción por los hogares pobres del resto del país.

Mirando el bienestar de los gobiernos, el gobierno nacional aumenta su bienestar, pero también lo hacen el de CABA y el del resto del país debido a que se incrementa la masa coparticipable, lo que mejora la situación fiscal de los gobiernos. 
III.4 - Sensibilidad de las externalidades fiscales a la regla de ajuste del mercado de trabajo

La presente subsección realiza un análisis de sensibilidad a salarios nominales constantes planteada en el anterior escenario. En esta subsección del trabajo, tomaremos el supuesto que los salarios reales se mantienen constantes, ajustándose de acuerdo al índice de precios de la canasta de consumo del hogar pobre de la CABA (indexados al IPC, es decir, [w/IPC] $\geq 1$ ], y cuya descomposición puede observarse en el Anexo II). Esto permite mantener el poder de compra de las canastas de consumo de acuerdo al IPC de la canasta del hogar pobre de CABA.

La Tabla 6 muestra que los resultados del modelo con la misma proporción de capital móvil $(\theta=0.12)$ son sensibles a la regla de ajuste del salario, especialmente cuando se analiza el bienestar de los agentes. Esto se produce como consecuencia de la aplicación del salario real constante, puesto que el efecto de su adopción eleva el nivel de precios y la tasa de desempleo en todas las simulaciones en todas las regiones; reforzando incluso las efectos spillover fiscales en sentido negativo.

En líneas generales, la indexación del salario para mantener el poder de compra del mismo, refuerza los efectos negativos sobre las variables como consecuencia del aumento en el nivel general de precios. Por lo tanto, el salario real constante provoca una mayor caída del PBI y sus componentes por el lado de la demanda. También se refuerzan la caída en las tasas de ganancia de los sectores y el bienestar del resto de los agentes (hogares y gobiernos).

En líneas generales, el escenario real refuerza los efectos negativos sobre las variables producto del aumento en el nivel general de precios. Por lo tanto, el salario real constante provoca caída de PBI y el bienestar para los agentes.

En particular puede observarse en la comparación con los resultados de la Tabla 5, que la tasa de desempleo es mayor en ambas regiones (y en todas las simulaciones) ya que el salario real está fijo (a diferencia del escenario nominal donde los salarios nominales estaban fijos pero los reales caían). Esto deteriora los términos de intercambio de Argentina y produce que los hogares disminuyan su bienestar en la comparación con el caso de salarios nominales.

En las tres simulaciones las políticas pierden efectividad dado que el bienestar del gobierno que eleva los impuestos es menor en el escenario de salarios reales. Lo mismo ocurre con las externalidades fiscales sobre los restantes gobiernos, así como también se refuerzan los efectos negativos sobre los hogares. 


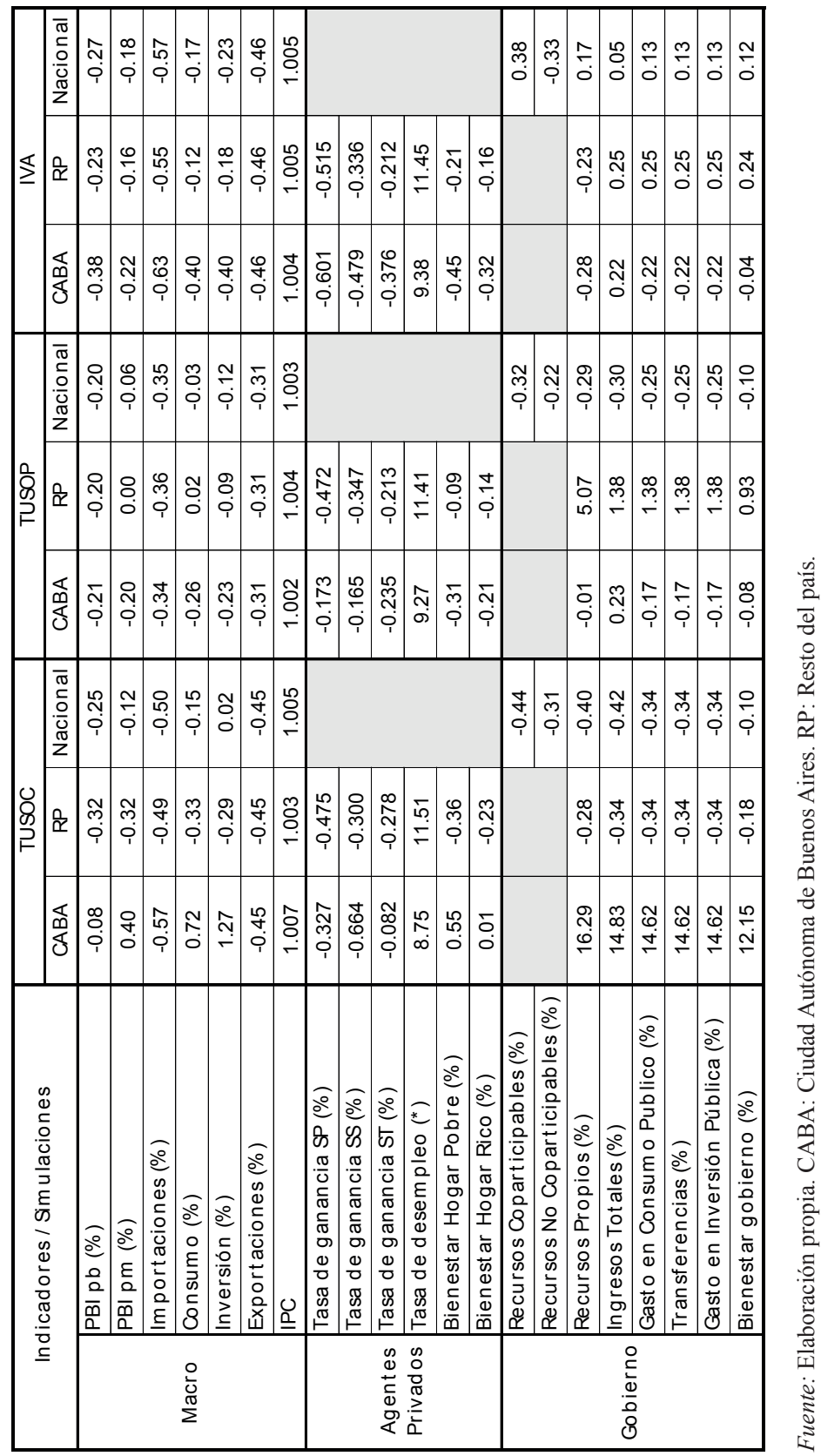




\section{III.5 - Sensibilidad de los efectos a la movilidad del capital}

La presente sección tiene como objetivo mostrar la sensibilidad de los resultados teniendo en cuenta el cambio en la movilidad del capital. Cabe recordar que el modelo supone que el factor trabajo es móvil entre sectores pero específico entre regiones, y que una proporción theta del capital es móvil entre regiones y entre sectores ${ }^{8}$. Ante un shock, el capital se reasigna de manera endógena teniendo en cuenta los cambios en las tasas de ganancia de los sectores. En particular, se simularon cuatro escenarios de movilidad del capital: 5\%, que supone baja movilidad; $12 \%$, que es el benchmark de calibración para Argentina siguiendo a Chisari et. al. (2010); 18\%, que supone movilidad moderada y 90\%, para ver las reacciones con una elevada movilidad.

Antes de discutir los resultados de la sensibilidad, analicemos qué pasa en los extremos; es decir, en presencia de capital específico por región y sector (no movilidad del factor) y bajo perfecta movilidad del capital (sin tener en cuenta la posibilidad de sustitución de los agentes a nivel de consumo). Si el capital es específico en la región y en el sector, los propietarios del capital no pueden eludir un impacto negativo en la tasa de ganancia de un sector moviéndose hacia otro sector o región más rentable. Si, en cambio, el capital es totalmente móvil, los propietarios del capital pueden eludir un impacto negativo en la tasa de ganancia e ir a sectores más rentables; lo que produce una igualación de las tasas de ganancia entre sectores y regiones.

Analicemos ahora qué pasa en casos intermedios ante un impacto negativo en las tasas de ganancia en los sectores de una región. El impacto negativo provoca que el capital sea menos rentable, lo que produce que los sectores se contraigan. Esto implica que los sectores con mayor caída en la tasa de ganancia expulsen parte del capital móvil (la parte de capital específico está fija) a otros sectores más rentables que generalmente están en la otra región.

Dado que el trabajo, el capital específico y el capital móvil son complementarios en la función de producción, la salida de capital implica que caiga la produc-

\footnotetext{
${ }^{8}$ Para el trabajo se toma el supuesto que una fracción del capital es específica del sector y la región y el resto es una proporción móvil de capital que es sustituto en todos los sectores en ambas regiones simultáneamente. Un caso intermedio que no analiza el trabajo y sería interesante abordar en un futuro es la presencia de tres tipos de capital, específico del sector y la región, específico de los sectores pero móvil entre regiones y móvil entre regiones y sectores.
} 
tividad marginal del trabajo, lo que se traduce en un aumento del desempleo ${ }^{9}$. Esto impacta directamente de manera negativa sobre el nivel de actividad, provocando la caída del PBI de la región.

La Figura 3 muestra la trayectoria de las variaciones respecto al benchmark de las principales variables en la primera simulación cuando varía la movilidad del capital. Para el análisis de sensibilidad se muestra la reacción de las simulaciones en el escenario de salarios nominales. Las conclusiones en el escenario de salarios reales son idénticas al cambiar la movilidad.

Dado que el impacto de la política fiscal es negativo sobre las tasas de ganancia de la mayoría de los sectores (la excepción es el sector de servicios públicos que es quien recibe la recaudación por la manera de modelar al gobierno), se produce una disminución en el PIB pb (a costo de factores) de la CABA que se acentúa al aumentar la movilidad del capital. Esto es producto del impacto negativo sobre el salario real en los mercados de trabajo que acarrea la reasignación del capital entre las regiones y los sectores para igualar las tasas de ganancia entre los sectores y las regiones.

En la Figura 3 puede observarse que la magnitud de las externalidades fiscales se acentúa sobre los hogares del resto del país y los gobiernos provinciales y nacional a medida que aumenta la movilidad. El gobierno de la CABA mejora las cuentas fiscales regionales ocurriendo lo inverso con el gobierno consolidado del resto de las provincias.

Puede concluirse que al aumentar la movilidad de capital en la simulación (TUSOC) se produce una caída de las tasas de ganancia de los sectores más relevantes (servicios), lo que genera que se expulse capital de la región aumentando la tasa de desempleo y disminuyendo la actividad de la región. Se observa que al incrementarse la movilidad disminuyen las externalidades sobre el resto del país cuando CABA modifica los impuestos provinciales.

La Figura 4 muestra la trayectoria de las variaciones respecto al benchmark de las principales variables en la segunda simulación cuando varía la proporción de capital móvil. En el caso del aumento en los impuestos a la producción del resto del país por parte de los gobiernos provinciales, se observa que a medida que se incrementa la movilidad del capital, las externalidades fiscales sobre los agentes de CABA aumentan. Esto sucede dado que los hogares disminuyen su bienestar,

\footnotetext{
${ }^{9}$ Esto ocurre aún con el salario real cayendo, dado que este efecto no llega a compensar la caída del salario real.
} 
Figura 3. Sensibilidad de los resultados a la proporción del capital en la simulación TUSOC.
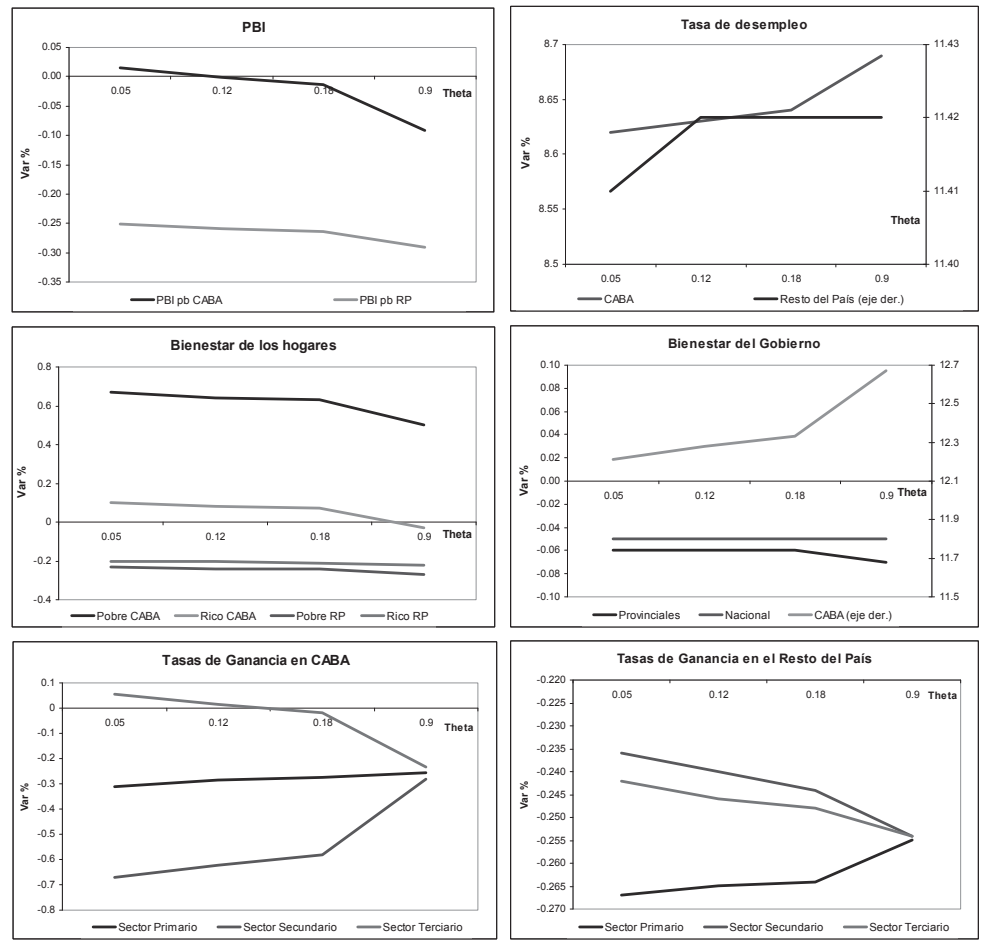

Fuente: Elaboración Propia

así como también caen los niveles de actividad de manera más pronunciada (con caídas en todos los componentes de la demanda agregada). La metodología de ajuste del bienestar de los agentes de CABA mediante el empeoramiento de las tasas de ganancia y el consecuente impacto sobre el mercado laboral es similar a los resultados de la primera simulación.

El cambio impositivo a medida que aumenta la movilidad del capital, genera que CABA disminuya aún más sus tasas de ganancia (repuntan la mayoría de los sectores del resto del país), expulsando capital móvil desde la CABA hacia el resto del país. Dada la complementariedad entre capital y trabajo, la región expulsora (receptora) de capital ve disminuir (aumentar) la productividad marginal del trabajo lo que genera un aumento (disminución) en la tasa de desempleo. Por lo tanto, el aumento de la movilidad provoca que los indicadores del resto del país 
Figura 4- Sensibilidad de los resultados a la proporción del capital en la simulación TUSOP.
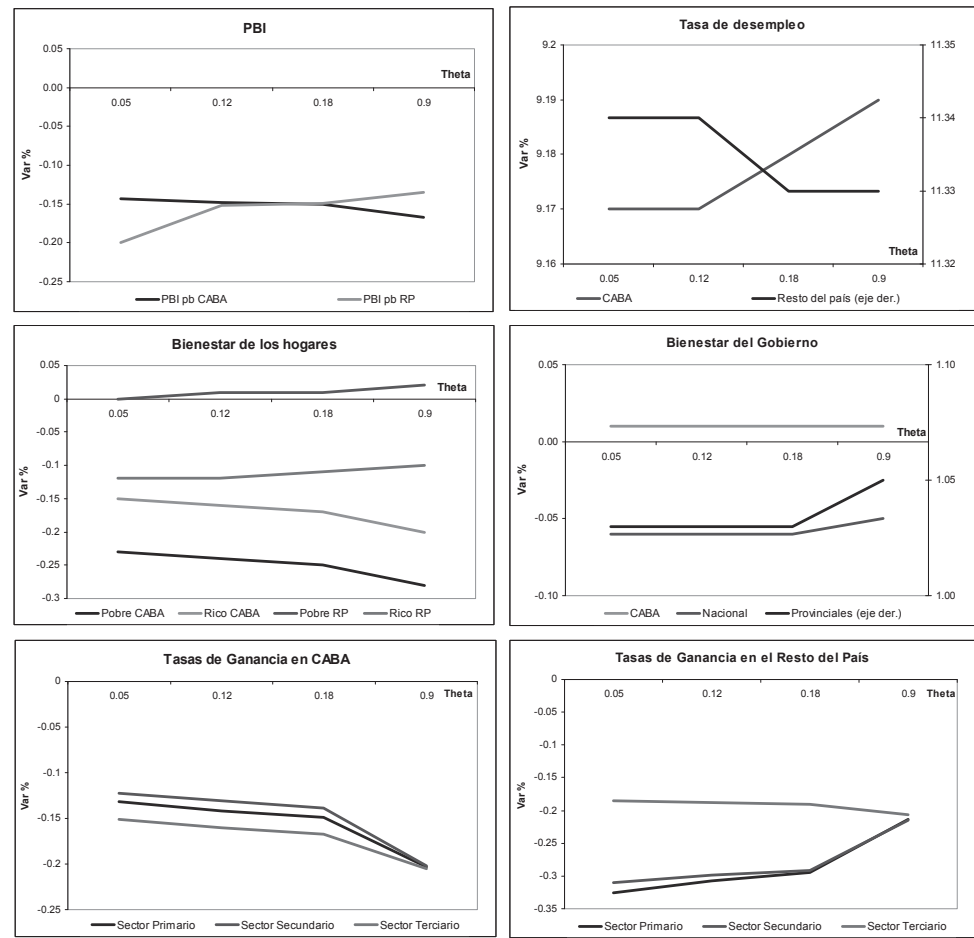

Fuente: Elaboración Propia

mejoren respecto a escenarios de baja movilidad, trasladándose los efectos con mayor incidencia sobre la CABA (y empeorando aún más sus indicadores).

La Figura 5 muestra las variaciones respecto al benchmark de las principales variables del modelo en la tercera simulación a medida que se aumenta la movilidad. Como se mencionó en el análisis de resultados de la simulación de aumento del IVA por parte del gobierno nacional, la región más afectada es la CABA. Esto surge dado que las tasas efectivas de pago de impuestos son más elevadas en esta región. Sin embargo, se observa que a medida que aumenta la movilidad del capital, hay una transferencia de bienestar desde las provincias a la $\mathrm{CABA}$, dado que los indicadores de la CABA mejoran sutilmente y empeoran simultáneamente los del resto del país. 
Figura 5. Sensibilidad de los resultados a la proporción del capital en la simulación IVA
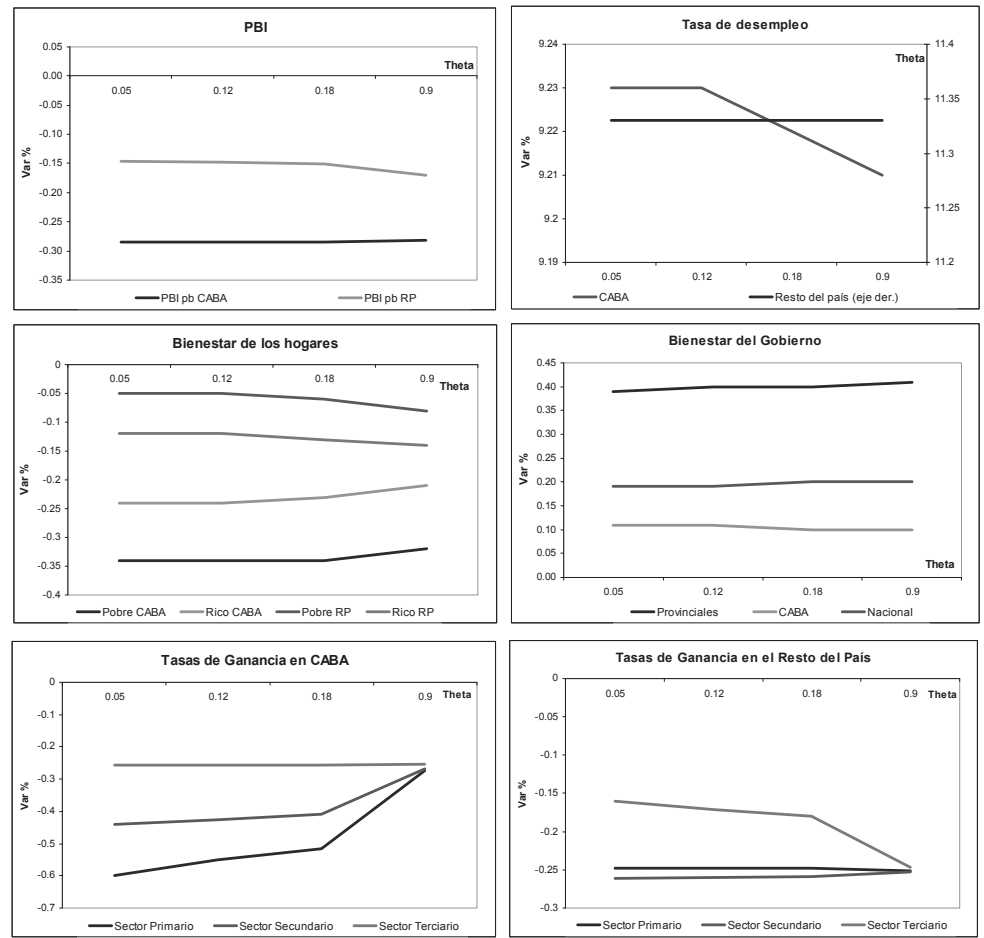

Fuente: Elaboración Propia

En los escenarios de baja movilidad del capital, la CABA percibe una mayor caída en las tasas de ganancia de sus sectores, por lo tanto, se eleva la tasa de desempleo (vía cambio en la productividad marginal del trabajo) empeorando el bienestar de los hogares. A medida que aumenta la movilidad, el capital móvil se reasigna desde la CABA (altas tasas efectivas) hacia el resto del país mejorando las tasas de ganancia de CABA y empeorando las tasas del resto del país. Esto tiene un impacto positivo en el mercado laboral de CABA (baja la tasa de desempleo) que hace que los hogares mejoren su bienestar respecto a los escenarios de baja movilidad. Como contrapartida, el efecto sobre el mercado laboral del resto del país no se percibe en la tasa de desempleo (permanece inalterada al segundo decimal) pero la disminución de las tasas de ganancias por el aumento del factor capital en la región provoca una caída en el PBI (dada la expulsión de capital móvil y 
en consecuencia la caída en la contratación de factores vía complementariedad en la función de producción) y en el bienestar de los hogares.

Respecto a los gobiernos, se percibe que el gobierno nacional mejora su bienestar por el aumento en la recaudación, y los gobiernos de la CABA y los provinciales mejoran vía incremento en la masa coparticipable.

\section{CONCLUSIONES}

El trabajo presenta evaluaciones de impacto de cambios en la política fiscal a nivel nacional y regional mediante un modelo de equilibrio bi-regional para Argentina que considera a la Ciudad de Buenos Aires (CABA) y al resto del país como una región agregada. Se simularon tres escenarios equivalentes en monto de recaudación: aumento del IVA (recaudado por el gobierno nacional) y un aumento de los impuestos a la producción provinciales (en CABA y en el resto del país por separado).

Se observa en los resultados que modificaciones en los impuestos provinciales de una región generan externalidades fiscales negativas sobre la otra región. Las externalidades fiscales interregionales son más acentuadas sobre el nivel de actividad y el bienestar de los agentes cuando aumentan los impuestos provinciales en CABA que cuando se produce en el resto del país.

Cuando cambia la política fiscal nacional en un impuesto coparticipable y sin efecto cascada como lo es el IVA, se observa que las externalidades fiscales son más importantes en la CABA que en el resto del país. Así, empeoran las condiciones en el mercado laboral de la CABA (mejoran en el resto del país) y se produce una transferencia de factores y bienestar desde la CABA hacia el resto del país. Esto es producto de las elevadas tasas efectivas que posee la región respecto al resto de Argentina.

Estos resultados fueron obtenidos suponiendo que existían condiciones de salario nominal mínimo constante en el mercado laboral (por la presencia de desempleo es crucial la inclusión de una regla de indexación salarial). Es por esto que se estudia en el trabajo cómo cambian los resultados de las simulaciones al suponer la regla de indexación que considere salarios reales constantes. Se observa que la tasa de desempleo es mayor en ambas regiones producto de que el salario real está fijo, lo que impacta directamente sobre los hogares que ven disminuir aún más su bienestar. En las tres simulaciones los efectos negativos se refuerzan en ambas 
regiones y las políticas pierden efectividad, dado que el bienestar del gobierno que eleva los impuestos es menor en el escenario de salarios reales.

Como los resultados son sensibles a la movilidad del capital, se incluyen en el trabajo cuatro escenarios de proporción del capital móvil en la función de producción (baja, moderada y alta movilidad). Los resultados son interesantes porque muestran asimetría en el análisis de impuestos regionales. Las conclusiones de la primera simulación se basan en que cuando CABA cambia los impuestos, las externalidades fiscales sobre la otra región van disminuyendo a medida que aumenta la movilidad, empeorando los indicadores de la región. En cambio, cuando el gobierno del resto del país pone el impuesto, los efectos negativos se acentúan sobre CABA a medida que se incrementa la movilidad, mejorando a su vez los indicadores del resto del país. Por último, la CABA tiene menores pérdidas en escenarios de elevada movilidad cuando el gobierno nacional aumenta el IVA; en efecto se observa que mejora el bienestar de la región y cae más en el resto del país. Esto ocurre debido a la composición industrial de la CABA y las alícuotas efectivas pagadas por las regiones. Estas conclusiones fueron presentadas en el escenario de salarios nominales pero son idénticas en el escenario de salarios reales.

Como se mencionó en el trabajo, futuras líneas de investigación deberían analizar el caso de movilidad interregional del trabajo, es decir, que el trabajo deje de ser específico en la región; así como también se podría analizar el caso de capitales específicos de las regiones pero móviles entre sectores de una misma región.

\section{APÉNDICE: ESTRUCTURA DEL MODELO DE EQUILIBRIO GENERAL}

Esta sección presenta una versión simplificada del modelo de equilibrio general. Consideremos una economía con $H$ hogares (en nuestro caso dos por región divididos por grupo de ingreso). La función de utilidad depende de bienes y servicios domésticos de las $j$ regiones $\left(c_{j}\right)^{10}$, bienes importados $(m)$, bonos en tenencia de los hogares $(b)$ y la oferta laboral $\left(L_{j}^{s}\right)$.

Cada hogar maximiza su función de utilidad $\left[u_{H}\left(c_{l}, c_{2}, m, b, L_{j}{ }^{s}\right)\right]$ sujeto a su restricción presupuestaria. Dadas las condiciones de óptimo, los agentes igualan la tasa marginal de sustitución de todos los bienes de la canasta con los correspondientes precios relativos. La recta de balance puede escribirse como:

${ }^{10}$ En el trabajo se diferencian las regiones CABA $(c 1)$ del resto del país $(c 2)$. 


$$
\text { [1] } \sum_{j=1}^{2}\left(1+t_{n}+t_{j}\right) p_{j} \mathrm{c}_{j}+\mathrm{p}_{m} \mathrm{~m}+p_{b} b=\sum_{j=1}^{2} \mathrm{w}_{j} \mathrm{~L}_{j}^{\mathrm{s}}+\sum_{j=1}^{2} \pi_{j} \eta_{j}+\sum_{j=1}^{2} r_{j} K_{j} \varphi_{j}+p_{b} b_{0}
$$

Donde $w_{j}$ son los salarios percibidos en la j-ésima región, $L_{j}^{s}$ es la oferta de trabajo en la j-ésima región y $\pi_{j}$ los beneficios percibidos en la región $j$. Las proporciones $\eta_{j}$ y $\theta_{j}$ representan las ponderaciones de los agentes domésticos en los beneficios y en el capital $(0<\eta, \varphi<1)$. La ecuación [1] supone que los consumidores solo pagan impuestos nacionales y provinciales en la compra de bienes domésticos. Ésta es una simplificación, dado que los hogares en el modelo pagan otros tipos de impuestos tal como se observa en la economía. El último término representa los bonos iniciales en las carteras de los hogares. El modelo general incluye toma de decisiones por parte de los hogares en la inversión privada.

La condición de equilibrio en el mercado de cada bien $j$ para los productores viene dada por [2]:

$$
x_{j}+\sum_{i=1}^{2} \mathrm{c}_{j, i}=\mathrm{F}\left(L_{j}, K_{j}\right)
$$

Donde $\mathrm{F}$ es la función de producción (que depende de los factores demandados) de bienes domésticos $c_{j}$ producidos en la j-ésima región y $x_{j}$ son las exportaciones al resto del mundo.

Los beneficios de la industria $j$ son:

$$
\pi_{j}=\mathrm{p}_{j}\left(x_{j}+\sum_{i=1}^{2} c_{j, i}\right)-\mathrm{w}_{j} L_{j}^{d}-\mathrm{r}_{j} K_{j}^{d}
$$

donde $r_{j}$ indica la remuneración al capital en la j-ésima región $y w_{j}$ los salarios. Las condiciones de máximo implican: ${ }^{11}$

$$
\begin{gathered}
\mathrm{p}_{j} \mathrm{~F}_{\mathrm{K}_{j}}-\mathrm{r}_{j}=0, \\
p_{j} \mathrm{~F}_{\mathrm{L}_{j}}-\mathrm{w}_{j}=0,
\end{gathered}
$$

\footnotetext{
${ }^{11}$ Se supone que $\mathrm{F}$ posee un grado de homogeneidad menor a uno y hay complementariedad en la función de producción a nivel de insumos.
} 
Donde los niveles de capital y trabajo se determinan de manera óptima. En equilibrio se iguala la demanda a la oferta de factores, por ejemplo la demanda de trabajo de la j-ésima región debe igualarse a la oferta laboral proveniente de las $I$ regiones.

$$
\begin{aligned}
& L_{j}^{d}=\sum_{i=1}^{2} L_{i}^{s}, \\
& K_{j}^{d}=\sum_{i=1}^{2} K_{i}^{s}
\end{aligned}
$$

En modelos con desempleo como el desarrollado, la ecuación [6] se reemplaza por una regla de indexación de salarios, por ejemplo $\mathrm{w} \geq 1$, con salarios nominales mínimos o algún índice de precios para fijar el salario real constante. Los gobiernos de CABA y provinciales del resto del país tienen la siguiente restricción presupuestaria:

$$
t_{j} p_{j} \mathrm{c}_{j}+p_{b} b_{0}^{G_{j}}+T=\mathrm{w}_{j} \mathrm{~L}_{j}^{\mathrm{G}_{j}}+p_{b} b^{G_{j}} \operatorname{con} j=1,2 .
$$

El lado izquierdo representa la recaudación de impuestos locales, sumado a las ventas de bonos y la coparticipación recibida por el gobierno nacional. El lado derecho representa las contrataciones laborales y las compras de bonos (por lo tanto la posición neta viene dada por $b^{G}-b_{0}^{G}$ ). Es importante tener en cuenta que, los gobiernos no participan de manera activa en los mercados de bienes y servicios en esta simplificación del modelo, cosa que sí ocurre en el modelo general. En el caso general, el gobierno recauda impuestos y los utiliza no solo para contratar trabajadores y pagar deuda sino que también consume e invierte en bienes y servicios.

El sector público nacional tiene la siguiente restricción presupuestaria:

$$
\sum_{j=1}^{2} t_{n} p_{j} \mathrm{c}_{j}+\sum_{j=1}^{2} \mathrm{t}_{\mathrm{x}} x_{j}+p_{b} b_{0}^{G}-T=\sum_{j=1}^{2} \mathrm{w}_{j} \mathrm{~L}_{j}{ }^{\mathrm{G}}+p_{b} b^{G} \quad \text { con } j=1,2
$$

El lado izquierdo representa las fuentes de financiamiento del gobierno nacional que incluye impuestos nacionales a los bienes de consumo, exportables y ventas de bonos netas de coparticipación. En esta versión simplificada las utiliza para contratar trabajadores, mientras que en la versión general puede consumir e invertir en bienes. 
En esta versión resumida del modelo, la balanza comercial puede resumirse como:

$$
p^{x} x=p_{m} m+\sum_{j=1}^{2}\left(1-\varphi_{j}\right) r_{j} K_{j}+\sum_{j=1}^{2}\left(1-\eta_{j}\right) \pi_{j} .
$$

Cabe destacar que este modelo simplificado tiene un importante supuesto (en el modelo general no se toma) que implica que el sector externo no compra/ vende bonos a los agentes del país.

\section{REFERENCIAS BIBLIOGRÁFICAS}

Bhattarai, K., (2007), Welfare impacts of equal-yield tax reforms in the UK economy. Applied Economics, Vol. 39, pp. 1545-1563.

Brooke, A., D. Kendrick y A. Meeraus, (1992), GAMS: A User's Guide, Release 2.25, Scientific Press.

Cardenete Flores, M., (2009), Federalismo fiscal a partir de un modelo de equilibrio general aplicado: Andalucía vs. España. Revista de Estudios Regionales. Vol ext. 7, pp. 359-366.

Cardenete Flores, M. y Sancho F., (2001), Modelos de equilibrio general aplicado para las economías regionales, IV Encuentro de Economía Aplicada, Reus, junio.

Cardenete Flores, M. y Sancho F., (2002), An Applied General Equilibrium Model to Assess the Impact of National Tax Changes on a Regional Economy, Economic Working Papers en Centro de Estudios Andaluces E2002/13, Centro de Estudios Andaluces.

Chisari, O. et al., (2010), Un modelo de equilibrio general computable para la Argentina 2006, Serie de textos de discusión N 63. Instituto de Economía. FACE- UADE.

Diao X., Diaz-Bonilla, E., Robinson, S., y Orden, D., (2005), Tell Me Where It Hurts, An' I'll Tell You Who To Call: Industrialized Countries, Agricultural Policies And Developing Countries. IFPRI Discussion Paper 84. Washington, D.C., International Food Policy Research Institute.

Flegg A. y Webber, C., (2000), Regional size, regional specialization and the FLQ formula, University of the West of England, Bristol.

Flegg, A. y Webber, C., (1997), On the appropiate use of location quotients in generating regional Input-Output tables: Reply, University of the West of England, Bristol.

Jensen et. al., (1979), Regional Economic Planning, Croom Helm, Londres.

Mastronardi, L. y Romero, C., (2012), Estimación de matrices insumo producto 
regionales mediante métodos indirectos. Una aplicación para la ciudad de Buenos Aires, Documento de trabajo, MPRA paper 37006, University Library of Munich, Alemania.

Mastronardi, L. y Romero, C. y Chisari, O., (2012), Building an input output model for Buenos Aires City, MPRA paper 40028, University Library of Munich, Alemania.

Robinson, S., Cattaneo, A. y El-Said, M., (2001), Updating and Estimating a Social Accounting Matrix Using Cross Entropy Methods, Economic Systems Research 13, pp. 47-64.

Rutherford, T., (1999), Applied General Equilibrium Modeling with MPSGE as a GAMS Subsystem: An Overview of the Modeling Framework and Syntax, Computational Economics, Vol.14, Nos. 1-2. 